\title{
LA PARTICIPACIÓN DIRECTA DE LOS CIUDADANOS EN LA CONSTITUCIÓN ESPAÑOLA Y LAS CONSULTAS POPULARES EN EL ÁMBITO ESTATUTARIO
}

\author{
M. ${ }^{a}$ ISABEL ÁLVAREZ VÉLEZ
}


SUMARIO

I. ACERCA DE LA DEMOCRACIA Y LA PARTICIPACIÓN DIRECTA DE LOS CIUDADANOS. II. EL REFERÉNDUM COMO VÍA DE PARTICIPACIÓN DIRECTA EN LA CONSTITUCIÓN DE 1978. III. LAS CONSULTAS POPULARES EN LOS ESTATUTOS DE AUTONOMÍA, ESPECIAL REFERENCIA AL CASO CATALÁN. 1. La regulación autonómica de las consultas populares y la intervención del Tribunal Constitucional. 2. La utilización en Cataluña de la competencia en consultas populares. IV. A MODO DE CONCLUSIÓN. 


\title{
LA PARTICIPACIÓN DIRECTA DE LOS CIUDADANOS EN LA CONSTITUCIÓN ESPAÑOLA Y LAS CONSULTAS POPULARES EN EL ÁMBITO ESTATUTARIO
}

\author{
M. ${ }^{a}$ ISABEL ÁLVAREZ VÉLEZ* \\ Profesora Propia Ordinaria de Derecho Constitucional \\ Facultad de Derecho (ICADE) \\ Universidad Pontificia Comillas
}

\section{INTRODUCCIÓN: ACERCA DE LA DEMOCRACIA Y LA PARTICIPACIÓN DIRECTA DE LOS CIUDADANOS}

La democracia no sólo es fundamento de la legitimidad del orden constitucional, sino también principio de legitimación del ejercicio del poder político. El sistema democrático debe caracterizarse por un grado real y organizado de acceso de todos los ciudadanos al sistema político, maximizando la participación ciudadana en los asuntos públicos. Los ciudadanos deben ser actores y autores del ordenamiento jurídico. De esta forma concebido, el principio democrático reviste sin duda una naturaleza compleja, donde el elemento representativo puede conjugarse en diversos grados con la manifestación directa de la voluntad popular ${ }^{1}$.

${ }^{*}$ M. ${ }^{a}$ Isabel Álvarez Vélez. Departamento de Disciplinas Comunes. Profesora Propia Ordinaria de Derecho Constitucional. Alberto Aguilera, 23 - 28015 Madrid. Correo electrónico: mba@ comillas.edu

${ }^{1}$ Cascajo Castro, J. L., «El Estado democrático: materiales para un léxico constitucional español», Revista Española de Derecho Constitucional, núm. 69, septiembre-diciembre 2003, págs. 125 y 126. 
Las sociedades occidentales contemporáneas están regidas mayoritariamente por sistemas democráticos de carácter constitucional parlamentario, cuyos principios políticos fundamentales, a riesgo de una generalización y sistematización excesiva, podrían resumirse en dos puntos: el sometimiento del poder público a la ley, lo que conduce al establecimiento del Estado de Derecho, y la participación ciudadana en los órganos que ostentan potestades públicas, desarrollo del Estado democrático.

La población, elemento del Estado, se configura, desde el punto de vista político-constitucional en el concepto de «pueblo», protagonista de su propio destino, responsable de su suerte, depositario de la soberanía. Pero, las grandes masas de población y la complejidad de los asuntos públicos han hecho prácticamente inviable una participación directa del ciudadano en la vida política. El ideal democrático de la pólis ateniense, en cuya Asamblea participaban todos los hombres libres, ha quedado en los libros de Ciencia Política como modelo de ciudad-Estado. La democracia contemporánea es necesariamente representativa, elegidos los miembros de los órganos locales, regionales, nacionales o supranacionales, a través de elecciones. Las garantías de una democracia transparente se sitúan en el sufragio universal, la periodicidad de las elecciones y otros mecanismos de control político.

Desde el presupuesto de que la democracia representativa constituye un elemento necesario del actual Estado democrático, se ha pasado con demasiada frecuencia a una descalificación de la democracia directa como imposible democracia de identidad, y a una pérdida de la obligada concepción dialéctica entre el concepto de democracia como proceso de representación y la idea de la misma como optimización de la participación. El resultado es en ocasiones la aceptación acrítica de un modelo interpretativo que tiende a reducir la naturaleza democrática del Estado a los procesos de legitimación de los órganos titulares del poder y a la consagración de la igualdad formal de derechos políticos, entendidos incluso, en su versión más reducida, como meros derechos de sufragio ${ }^{2}$.

Pero, en todo caso, muchas de las propuestas tendentes a articular una mayor participación ciudadana en los asuntos públicos caen en la trampa perfeccionista que oculta políticamente lo poco meditado de las ideas y que acaba por convertir al ciudadano democrático en simple cliente del mercado político monopolizado por los partidos ${ }^{3}$.

No cabe duda, sin embargo, de la importancia de la información y la participación ciudadana. En las sociedades actuales, ciertamente complejas, se ha

\footnotetext{
2 Ídem, págs. 126 y 127.

3 Ídem, págs. 127 y 128.
} 
generalizado la idea de que la democracia conlleva que los ciudadanos, bien por sí mismos, bien a través de los medios de comunicación social, puedan conocer cómo actúan los poderes públicos y, de ese modo, poder de alguna manera controlarles, descubrir un mal funcionamiento y ayudar a mejorar la calidad de la gestión pública.

Además, si bien es cierto que hoy disponemos de una ciudadanía con un nivel educativo más elevado, lo que le confiere una mayor capacidad para la intervención política con criterio y rigor, no es menos cierto que la generalidad de los ciudadanos no disponen ni de información suficiente en todos los campos ni de interés para decidir determinados asuntos, ya que su vocación no es vivir para la política ${ }^{4}$.

Sin embargo, la identificación mimética entre Constitución y democracia no es exacta ${ }^{5}$. El contenido del principio democrático aparece configurado por la Constitución misma, es decir, por la idea de democracia que la Constitución proclama para su propia realización ${ }^{6}$. Se trata, en cierto modo, de una paradoja, ya que para la Constitución es Estado democrático no el que promueve cualquier concepto de democracia, sino sólo el que la propia Constitución diseña, pero, al mismo tiempo, el Estado constitucional ha de aspirar a la realización del principio democrático.

Precisamente, el Estado constitucional puede admitir en aras de la pervivencia del Estado democrático, fórmulas que no sean esencialmente democráticas. La función básica de una Constitución es separar ciertas decisiones del proceso democrático, es decir, atar las manos de la comunidad ${ }^{7}$. Ello constituye una paradoja, pero es una paradoja más del propio Estado constitucional ${ }^{8}$.

${ }^{4}$ Pau i Vall, F. y Sánchez i Picanyol, J., «Democracia y nuevas tecnologías», en Pau I Vall, F. (coord.), Parlamento y sistema electoral, VI Jornadas de la Asociación Española de Letrados de Parlamentos, Pamplona, 1999, págs. 440 y 441.

5 Como señala Aragón, la pretensión de la Constitución es, precisamente, la de juridificar la democracia, la de unir democracia y Estado de Derecho. Vid. Aragón ReYes, M., «La eficacia jurídica del principio democrático», Revista Española de Derecho Constitucional, núm. 24, 1988, pág. 30.

${ }^{6}$ Ídem, pág. 31.

7 Holmes, S., «El precompromiso y la paradoja de la democracia», en Elster, J., Constitucionalismo y democracia, México 1999, pág. 217.

${ }^{8}$ Es habitual que la doctrina emplee la historia de Ulises y las sirenas para explicar que la Constitución supone, principalmente, autorrestricción, limitación del poder del pueblo en aras de la pervivencia de la propia democracia. Así, Elster señala que las constituciones son mecanismo de precompromiso o autorrestricción, elaboradas por el cuerpo político con el fin de protegerse a sí mismo contra su previsible tendencia a tomar decisiones imprudentes. Vid. Elster, J., Ulises desatado. Estudios sobre racionalidad, precompromiso y restricciones, Barcelona, 2002, págs. 111 y 112. También, debemos recordar que el Estado constitucional se construye sobre la base no sólo del temor al poder absoluto encarnado en el monarca, sino también del propio temor al Parlamento, 
Para Aragón la opción de la norma constitucional a favor de la democracia representativa, como proyección del principio democrático, no desvirtúa este principio, sino que lo confirma. La tópica contraposición entre democracia directa (como democracia auténtica) y democracia representativa (como defectuosa democracia) no puede salvarse acudiendo al también tópico expediente de razonar que una cosa es el ideal, la teoría, y otra la práctica, y que la mala o defectuosa realización práctica no puede refutar la teoría, ya que no puede hablarse de una primacía o de un "plusvalor democrático» de la democracia directa frente a la representativa-indirecta, sino, por el contrario, de que esta última, esto es, la representativa, constituye la forma propia de la democracia, sobre todo, de la democracia como modo de ejercicio del poder «constituido» ${ }^{9}$. Porque, además, no hay comunidad de hombres libres si no hay distinción entre gobernantes y gobernados, y por lo mismo si no hay limitación del poder y responsabilidad de los gobernantes; y es la representación la que hace posible que todo ello pueda realizarse ${ }^{10}$.

Igualmente, Acosta Sánchez se refiere a esta cuestión cuando manifiesta que hay tres supuestos en los que no es posible que la Constitución se dé como Ley suprema: en primer lugar, en el caso de representación total y única del titular de la potestad legislativa por un Parlamento (paradigma británico); en segundo lugar, cuando se preserva el principio de inmediación entre el titular de la potestad legislativa y el ejercicio de ésta mediante el referéndum legislativo obligatorio de carácter general (paradigma helvético a escala cantonal), y en tercer lugar, en el supuesto de democracia "pura», existente sólo como tipo teórico, aspiración racional e ideal ${ }^{11}$. En este sentido dicho autor considera que la fórmula de democracia directa no es viable dentro de un Estado constitucional, ya que dicha fórmula determina, inexorablemente, que la Constitución pierda su propio carácter de norma suprema. El Estado constitucional es un Estado de representaciones ${ }^{12}$.

es decir, a la postre, a las decisiones (bumores) del pueblo. Ello es fácilmente apreciable en la propia construcción del Estado constitucional en los Estados Unidos de América, donde se construye finamente la doctrina de The few, de manera que se garantiza la posición de las minorías respecto de las mayorías. A este respecto, puede verse Gargarella, R., La justicia frente al gobierno. Sobre el carácter contramayoritario del poder judicial, Barcelona, 1996.

9 Aragón Reyes, M., «La eficacia jurídica del principio democrático», cit., pág. 39.

10 Aragón Reyes, M., Estudios de Derecho constitucional, Madrid, 2013, pág. 482.

11 Acosta SÁNCHez, J., «La articulación entre representación, Constitución y democracia: génesis, crisis actual y Constitución española», Revista de Estudios Políticos, núm. 86, 1994, pág. 113.

12 Ídem, pág. 115. 
En las páginas siguientes estudiaremos, la participación directa, esto es el referéndum, en nuestra Constitución como proyección del derecho fundamental del art. 23 CE y, por otra parte, la previsión en el ámbito autonómico de la participación ciudadana a través de consultas populares que no es más que un principio de democracia participativa pues en virtud del art. 9.2 CE corresponde a los poderes públicos «facilitar la participación de todos los ciudadanos en la vida política, económica, cultural y social», mandato que afecta por ende a las Comunidades Autónomas ${ }^{13}$. Las reformas en este punto de los Estatutos de Autonomía a partir de 2006 y la aprobación de Leyes autonómicas sobre participación ciudadana no son claramente proyección del derecho constitucional en cuestión, pero sí constituyen derechos estatutarios que actúan en el ámbito autonómico ${ }^{14}$. De esta manera, se ha utilizado la competencia en consultas populares para celebrar «referéndums» secesionistas, utilizando el principio democrático para subvertir el orden constitucional. Pero vayamos por partes, comencemos por estudiar el mandato representativo en nuestro sistema y la regulación del referéndum para tratar posteriormente el tema autonómico.

\section{EL REFERÉNDUM COMO VÍA DE PARTICIPACIÓN DIRECTA EN LA CONSTITUCIÓN DE 1978}

La Constitución española de 1978 declara, en el art. 66, que las Cortes Generales, formadas por el Congreso de los Diputados y el Senado, representan al pueblo español. Declaración que enlaza con el art. 1.2, de modo que «queda conectado el órgano parlamentario con la soberanía popular» ${ }^{15}$. No olvidemos que, del «pueblo emanan los poderes el Estado» a través del principio de representación, que otorga a las Cortes legitimidad democrática, de modo que los

13 Un estudio interesante sobre estos temas con numerosas citas jurisprudenciales puede verse en EsPaRZa MARTínez, B., La participación política como derecho fundamental en la Constitución de España y de Europa, México, 2008.

14 En este sentido el Tribunal Constitucional ha señalado que «nuestra Constitución permite que las Asambleas legislativas de las Comunidades Autónomas establezcan sus propias políticas diferenciadas en las materias de su competencia y que, al hacerlo, determinen una diversidad de regímenes jurídicos en cada una de ellas con los efectos consiguientes sobre los ciudadanos de cada territorio autonómico, efectos que podrán producirse a través de los diversos medios, instrumentos o técnicas que son inherentes al ejercicio de la autonomía política (declaraciones programáticas, formulación de derechos subjetivos de los destinatarios de las actuaciones o adopción de medidas concretas, entre otras posibles)»: STC 247/2007, de 12 de diciembre de 2007, F. J. 14.

15 Solé Tura, J., y Aparicio Pérez, M. A., Las Cortes Generales en el sistema constitucional, Madrid, 1988, pág. 27. 
actos de las Cortes constituyen actos del pueblo. Por ello, la Constitución, al configurar a la Monarquía como parlamentaria, la acerca al pueblo, depositario de la soberanía nacional, que renueva periódicamente su representación en las Cortes. Nuestra Constitución en su art. 67.2 CE, establece que «los miembros de las Cortes Generales no estarán ligados por mandato imperativo», en virtud del cual se establecía una relación concreta entre el diputado y los electores que lo habían designado, de tal forma, que el diputado debía ajustarse en el ejercicio de sus funciones a las instrucciones recibidas por los electores. El modelo del mandato imperativo se proscribe, debido a su evidente rigidez y formalismo, y porque mostró progresivamente su inoperancia y desajuste en relación con las funciones que iban asumiendo los Parlamentos. Construir la posición jurídica del representante sobre el apoderamiento dificultaba la toma de decisiones y hacía imposible el planteamiento de cuestiones no previstas en los mandatos.

Por ello, el modelo de mandato variará, apareciendo el mandato representativo que pretende independizar al representante de las instrucciones de sus electores en su actuación parlamentaria, y no sólo en la emisión del voto. Así, sus derechos y libertades se tradujeron en una comprensión del mandato parlamentario que vetaba cualquier vínculo jurídico que ligara al representante con voluntad distinta a la expresada por la Cámara. En definitiva, se garantizaba su libertad en el desarrollo de su labor ${ }^{16}$.

La mencionada prohibición sólo puede tener un sentido claro: no hay sometimiento a ningún tipo de mandato ni instrucciones, porque el representante se debe únicamente a la representatividad que porta y que se configura en las urnas, en la voluntad política de un sujeto jurídico, el cuerpo electoral ${ }^{17}$. Lo que ahora se busca es que los elegidos respondan a la opción política que los ciudadanos han elegido ${ }^{18}$.

También, sin embargo, el sistema representativo es un sistema que ha mostrado sus deficiencias y que hoy se encuentra en franca crisis por la aparición del sistema de partidos. La teoría del mandato representativo supone que el diputado representa a la Nación en su totalidad, y no al grupo que lo ha elegido. Por tanto, los diputados no están sujetos al mandato imperativo: los electores los

16 Sobre las transformaciones que experimenta el contenido de la representación política con la llegada del Estado liberal a un sistema democrático, vid. Garrorena Morales, A., Representación politica y Constitución democrática (Hacia una revisión crítica de la teoría de la representación), Madrid, 1991, págs. 57 y ss.

17 De Vega, P., «Significado constitucional de la representación política», Revista de Estudios Políticos, núm. 44, 1985, págs. 32 y 33.

18 Portero Molina, J. A., «Sobre la representación política», Revista del Centro de Estudios Constitucionales, núm. 10, 1991, pág. 97. 
eligen, pero no les dan instrucciones. De ahí, que no puedan ser revocados por sus propios electores ${ }^{19}$.

Pero no hay que olvidar que en las Cortes Generales, diputados y senadores forman grupos parlamentarios, que a pesar de ser órganos de gestión pueden ser sin ninguna duda identificados con partidos políticos o al menos con formaciones políticas que se han presentado a unas elecciones. Por ello, la prohibición constitucional del mandato imperativo puede ser cuestionada, pues surge la lógica pregunta acerca de si la disciplina de voto que vincula a los parlamentarios al grupo que pertenecen, no es una nueva forma de mandato que supone una infracción del precepto constitucional. En este sentido, Álvarez Conde aprecia la introducción de prácticas parlamentarias que suponen modalidades de mandato imperativo a través de los especiales lazos de unión que ligan a los parlamentarios con los partidos políticos ${ }^{20}$. Entre estas prácticas se suelen mencionar las siguientes: la renuncia por escrito y en blanco de la condición del parlamentario cuando se rompa la disciplina, lo que parece indicar que el escaño es propiedad del partido; la renuncia del escaño cuando el parlamentario se pasa a otro grupo; etc. Es cierto que en ninguno de estos supuestos el parlamentario quedaría obligado jurídicamente a dimitir. La cuestión debe relacionarse con la ya mencionada crisis del mandato representativo ${ }^{21}$.

Para subsanar los errores e insuficiencias de la participación ciudadana, esto es del sistema de representación, se mantienen en los textos constitucionales instituciones de democracia directa para que los ciudadanos participen como gobernados, sin intermediarios en la vida pública. En definitiva, se les otorga la posibilidad de expresar su opinión en determinados asuntos, aunque sea de forma restringida, ya que en las sociedades actuales la democracia directa es un ideal irrealizable debido a la masificación. De hecho el establecimiento de un sistema representativo supuso la incompatibilidad con las fórmulas de democracia directa hasta que después de la Segunda Guerra Mundial el movimiento constitucionalista volvió a plantearse la cuestión ${ }^{22}$. Algunos países europeos utilizaron el referéndum para volver a las Constituciones vigentes antes de la guerra, para

19 Vid. al respecto Vallés, J. M. y Bosch, A., Sistemas electorales y gobierno representativo, Barcelona, 1997, págs. 19 y 20.

20 Álvarez Conde, E., Curso de Derecho Constitucional, Volumen I, Madrid, 1992, pág. 120.

${ }^{21} \mathrm{La}$ jurisprudencia del TC ha hecho referencia en varios momentos a este tema: Vid. GARRoRena Morales, A., op. cit., en especial págs. 23-37.

22 Torres Del Moral, A., Estado de Derecho y Democracia de Partidos, Madrid, 1991, pág. 354. Señala citando a Carré de Malberg que «la introducción de formas de participación popular directa no pretende únicamente dar satisfacción a las aspiraciones democráticas, sino que se inscribe en un movimiento de reacción frente al parlamentarismo absoluto». 
convocar un procedimiento constituyente o como en el caso de Italia o Bélgica optar por la forma de Gobierno, esto es, república o monarquía ${ }^{23}$.

La Constitución española de 1978 recoge dos formas de ejercicio de la soberanía al afirmar en el art. 23.1 que «los ciudadanos tienen el derecho a participar en los asuntos públicos directamente o por medio de representantes, libremente elegidos en elecciones periódicas por sufragio universal». El Tribunal Constitucional ha señalado que «la expresión "asuntos públicos" resulta aparentemente vaga y, a primera vista, podría llevar a una interpretación extensiva del ámbito tutelado por el derecho que incluyera cualquier participación en asuntos cuyo interés transcienda el ámbito de lo privado. Esta interpretación literal de la expresión no es, desde luego, la única posible, y no parece tampoco la más adecuada cuando se examina el precepto en su conjunto y se conecta con otras normas constitucionales. El art. 23.1 CE garantiza un derecho de participación que puede ejercerse de dos formas distintas, bien directamente, bien por medio de representantes ${ }^{24}$.

Junto a la fórmula de la representación política, nuestra Constitución admite también, como cauce de conformación y expresión de la voluntad general, la participación directa de los ciudadanos en los asuntos públicos, en «aquellos supuestos en los que la toma de decisiones políticas se realiza mediante un llamamiento directo al titular de la soberanía» ${ }^{25}$.

En nuestra Constitución se reconocen básicamente tres fórmulas de democracia directa. En primer lugar, la iniciativa legislativa popular, en segundo lugar, el sistema del Concejo abierto que se utiliza para la gestión de algunos municipios y, en tercer lugar, el referéndum. Vamos a hacer una breve referencia al referéndum, al entender que el Concejo abierto ${ }^{26}$ y la iniciativa legislativa popular ${ }^{27}$, aun siendo formas claras de participación directa, exceden el análisis que nos proponemos.

${ }^{23}$ Señala Aguiar que en la Constitución italiana se prevén todas las modalidades posibles de participación directa porque del referéndum celebrado el 2 de junio de 1946 no sólo se deduce un «no» a la Monarquía, sino «un deseo del pueblo italiano de llevar hasta sus últimos escalones la participación política recientemente conquistada»: Aguiar LuQue, L., Democracia directa y Estado constitucional, Madrid, 1977, pág. 188.

${ }^{24}$ STC 119/1995, de 17 de julio de 1995, F. J. 2.

25 Ídem, F. J. 3.

${ }^{26}$ Un buen estudio sobre el Concejo abierto puede verse en Alcón Yustas, M. F., «Una institución de democracia directa: el Régimen Municipal de Concejo abierto», Revista CUNAL (Revista de Administración Local), núm. 51, 1997, págs. 24-34.

${ }^{27}$ Sobre la participación de los ciudadanos es interesante el trabajo de CASTEllà Andreu, J. M. ${ }^{a}$, «Democracia participativa en las instituciones representativas: apertura del Parlamento a la sociedad», Cuadernos Manuel Giménez Abad, núm. 5, junio 2013, págs. 202-233 y sobre la iniciati- 
Señalábamos como tercera vía de participación directa el referéndum que consiste en la consulta al conjunto del cuerpo electoral, para que se pronuncie sobre una decisión política o sobre un texto a aprobar. Su función principal es complementar a las instituciones de democracia representativa y en este sentido conocer el sentir ciudadano de las decisiones de los poderes públicos, dotándoles de una legitimidad especial ${ }^{28}$.

Aunque el borrador del texto constitucional contenía tres tipos, consultivo, constitucional y legislativo, se suprimió este último en la discusión del proyecto, puesto que suponía la posibilidad de que el pueblo se pronunciara sobre el contenido de un proyecto o proposición de ley. La inclusión del referendo consultivo dentro del Capítulo II del Título III dedicado a la elaboración de las leyes siempre ha llamado la atención de la doctrina. Este hecho encuentra su explicación en que el art. 85 del Anteproyecto constitucional ubicado en ese mismo Capítulo incluía, además del referéndum consultivo actual, el referéndum legislativo y el abrogativo o, si se quiere, dos modalidades de referéndum legislativo mediante las cuales el cuerpo electoral se podía pronunciar sobre un proyecto de ley elaborado por las Cortes o sobre la derogación de una ley ${ }^{29}$.

La regulación de este tipo de consultas populares se encuentra recogida en la Ley Orgánica 2/1980, de 18 de enero, de regulación de las distintas modalidades de referéndum (LOMR), norma que se dictó en cumplimiento del art. 92.3 CE que establece que una «Ley Orgánica regulará las condiciones y el procedimiento de las distintas modalidades de referéndum previstas en la Constitución». La LOMR se elaboró con premura puesto que sólo a través de ella podría alguna zona del territorio acceder a la autonomía prevista en el art. $151 \mathrm{CE}$, lo que

va legislativa el estudio de Astarloa Villena, F., «La iniciativa legislativa popular en España», UNED. Teoría y Realidad constitucional, núm. 10-11, 2002-2003, págs. 273-322. La iniciativa legislativa popular está regulada en el art. 87.3 CE y desarrollada en la LO 3/1984, de 26 de marzo, reguladora de la iniciativa legislativa popular (modificada por la LO 4/2006, de 26 de mayo). De la misma forma todos los Estatutos de Autonomía reconocen la posibilidad de iniciativa legislativa popular, remitiendo su desarrollo a Ley autonómica, y no señalando número de firmas necesario, salvo el Estatuto de Extremadura que señala que la iniciativa será de «al menos 45.000 firmas acreditadas del censo para las elecciones a la Asamblea» (art. 26.4 LO 1/2011, de 28 de enero, de reforma del Estatuto de Autonomía de la Comunidad Autónoma de Extremadura).

28 Pérez Sola, N., La regulación constitucional del referéndum, Jaén, 1994, pág. 184. Vid. también Aguiar Luque, L., «Voz referéndum», en Aragón Reyes, M. (Dir.) y Aguado ReneDO, C. (Codir.), Constitución, Estado constitucional, partidos y elecciones y fuentes del Derecho. Temas básicos de Derecho constitucional, Tomo I, Cizur Menor (Navarra), 2011, págs. 148- 155.

29 Sobre el contenido del precepto del proyecto de Constitución relativo al referéndum puede consultarse Linde Paniagua, E. y Herrero Lera, M., «El referéndum: de las Leyes Fundamentales al Anteproyecto de Constitución», Revista de Estudios Políticos, núm. 2, 1978, págs. 87-106. 
preocupó especialmente a la clase política para el acceso de Andalucía a la autonomía ${ }^{30}$. Bien es sabido que los procesos autonómicos vasco y catalán llevaron una vía diferente puesto que los referéndums de ratificación de sus respectivos Estatutos se llevaron a cabo a través de Decretos- Leyes ${ }^{31}$.

El art. 2 de la LOMR señala que es «competencia exclusiva del Estado la convocatoria de consultas populares», tal como además se establece en el art. 149.1.32. ${ }^{a}$ CE. Corresponde al Rey convocar referéndum, a propuesta del Presidente del Gobierno, con autorización acordada en Consejo de Ministros y en los casos de referéndum consultivo se exigirá la autorización previa del Congreso de los Diputados por mayoría absoluta. Por su parte, cuando la convocatoria de la consulta afecte a la reforma constitucional será necesaria la comunicación previa a las Cortes Generales.

De esta forma los tres tipos de referéndum que están previstos en nuestra Constitución son el constituyente, el autonómico y el consultivo ${ }^{32}$. En lo que se refiere al referéndum constituyente se prevé para los casos de reforma parcial y total de la Constitución (arts. 167 y 168 CE respectivamente).

En lo que se refiere al referéndum consultivo está previsto en el art. $92 \mathrm{CE}$, así como en el art. 6 de la LOMR, en los siguientes términos: «El referéndum consultivo previsto en el art. $92 \mathrm{CE}$, requerirá la previa autorización del Congreso de los Diputados por mayoría absoluta a solicitud del Presidente del Gobier-

30 Tanto la preocupación de la clase política como el estudio de los acontecimientos que rodearon al referéndum andaluz puede consultarse OrTEga Álvarez, L., «La inconstitucionalidad de la reforma de la Ley Orgánica de referéndum», Revista de Administración Pública, núm. 97, 1982, págs. 171- 206.

${ }^{31}$ Decretos-Leyes 13/1979, de 14 de septiembre, y 14/1979, de 14 de septiembre, publicados en el BOE de 24 del mismo mes y año, y convalidados por el Congreso de los Diputados por acuerdo del 28 de septiembre, publicado en el BOE de 10 de octubre de 1979. Vid. sobre este tema Linde Paniagua, E., «Anotaciones a los Decretos-Leyes de convocatoria de los referéndums autonómicos en el País Vasco y Cataluña: vigencia de la Constitución y reserva de la Ley Orgánica», Revista de Administración Pública, núm. 89, 1979, págs. 411-417.

32 Están previstas hace años en nuestro sistema las consultas populares en el ámbito municipal tal como señala el art. 71 de la Ley 7/1985, de 2 de abril, Reguladora de las Bases del Régimen Local, en los siguientes términos: «De conformidad con la legislación del Estado y de la Comunidad Autónoma, cuando ésta tenga competencia estatutariamente atribuida para ello, los Alcaldes, previo acuerdo por mayoría absoluta del Pleno y autorización del Gobierno de la Nación, podrán someter a consulta popular aquellos asuntos de la competencia propia municipal y de carácter local que sean de especial relevancia para los intereses de los vecinos, con excepción de los relativos a la Hacienda Local». Vid. al respecto, IBÁÑ̃z MACíAs, A., El referéndum local en España: régimen jurídico, Cádiz, 2005. El Consejo de Estado se pronunció sobre este punto con ocasión del Dictamen 1070/2001, de 21 de junio, sobre el Proyecto Real Decreto regulador del procedimiento de autorización por el Gobierno de la Nación de las consultas populares municipales. 
no. Dicha solicitud deberá contener los términos exactos en que haya de pronunciarse la consulta». Como ya hemos señalado esta consulta exige el acuerdo del Consejo de Ministros dado que es imprescindible la convocatoria a través de Real Decreto $^{33}$. En varias ocasiones se han convocado referéndums consultivos, que se prevén constitucionalmente para las decisiones políticas de especial trascendencia, concepto que queda a criterio del Presidente del Gobierno ${ }^{34}$. Las dos ocasiones en que se han convocado este tipo de consulta han sido en 1986, sobre la permanencia de España en la OTAN y en 2005, sobre la Constitución Europea.

El último tipo de referéndum que se recoge en nuestro sistema es el autonómico. En este caso se prevén varios supuestos. En primer lugar, para ratificar la iniciativa autonómica estableciéndose que «el Gobierno procederá a la convocatoria de referéndum en el plazo de cinco meses. Celebrado el referéndum, si no llegase a obtenerse la ratificación por el voto afirmativo de la mayoría absoluta de los electores de cada provincia no podrá reiterarse la iniciativa hasta transcurridos cinco años» (art. 151.1 CE) ${ }^{35}$. En segundo lugar, para aprobar los Estatutos de Autonomía tal como se prevé en el art. 151. 2, 3..$^{\circ}$ y $5{ }^{\circ} \mathrm{CE}$ y en el art. 9 de la LOMR. En tercer lugar, el previsto en el art. 152. 2 CE y en el art. 10 de la LOMR para la modificación de los Estatutos de Autonomía. En este caso se «requerirá previamente el cumplimiento de los trámites de reforma establecidos en ellos o en su defecto de los que fueran precisos para su aprobación debiendo ser convocados en el plazo de seis meses desde el cumplimiento de los mismos». Estas consultas ya se han celebrado con motivo de las reformas de los Estatutos de Autonomía de Cataluña y Andalucía ${ }^{36}$. Y, finalmente, en cuarto lugar, el

${ }^{33}$ López GonZÁLEZ, J. L., «El referéndum nacional consultivo sobre decisiones políticas de especial trascendencia», Cuadernos constitucionales de la Cátedra Fabrique Ceriol, núm. 38/39, 2002, pág. 211.

${ }^{34}$ En este sentido se pronuncian Linde Paniagua, E. y Herrero Lera, M., op. cit., pág. 95. Vid. también en este sentido CruZ Villalón, P., «El referéndum consultivo como modelo de racionalización constitucional», Revista de Estudios Políticos, núm. 3, 1980, págs. 145-168.

${ }^{35}$ La exigencia de este último requisito, mayoría absoluta, complicaba sin duda el éxito de la consulta, pues no es exigencia en ninguno de los otros supuestos que hemos ido analizando. Es por ello, por lo que, como señalábamos anteriormente, se modificó la LOMR, a través de la LO 12/1980, permitiendo que si en alguna provincia no se hubiera obtenido esa mayoría, como sucedió en Almería, se sustituyera esa iniciativa a través de Ley Orgánica, previa solicitud de la mayoría de los Diputados y Senadores de la provincia o provincias en las que no se hubiera ratificado la iniciativa. Como señala Ortega para solucionar el problema creado se optó con esta modificación por introducir un mecanismo que «sin mencionarlo, contiene la filosofía «sustitutiva» del artículo 144, c), para remediar el fracaso de la iniciativa en Almería»: Ortega Álvarez, L., op. cit. pág. 192.

36 Vid. López GonZÁlez, J. L., El referéndum en el sistema español de participación política, Valencia, 2005, págs. 33 a 37 y 61 a 80. 
referéndum previsto en la Disposición transitoria cuarta CE para la incorporación de Navarra «al régimen autonómico vasco».

A estas alturas de la exposición convendría realizar una breve acotación terminológica. Son tres los términos, plebiscito, referéndum y consulta popular que se suelen utilizar como sinónimos. Aun cuando coloquialmente pueda hacerse, tanto política como jurídicamente presentan diferencias notables. Plebiscito es un término que debería quedar reservado a la consulta referida a la forma de Estado o en su caso sobre una modificación de la soberanía, mientras que referéndum se utiliza para hacer referencia a un acto del pueblo de aprobar una decisión ${ }^{37}$. Y en este sentido quizá habría que señalarse que el previsto en el art. $92 \mathrm{CE}$ en el que se convoca referéndum para la toma de «decisiones políticas de especial trascendencia», como los previstos en el art. 151 CE serían más bien plebiscitos que referéndum. Similar consideración podría hacerse de los previstos para la reforma constitucional en aquellos casos en que la reforma suponga un cambio político radical ${ }^{38}$.

El referéndum constituye una apelación al cuerpo electoral como titular de la soberanía, que tiene por objeto conocer su parecer sobre un determinado asunto, manifestado a través de un procedimiento electoral, y que implica el ejercicio de poder político, de forma que la opinión así manifestada constituirá una manifestación de la voluntad popular. La finalidad del llamamiento es por tanto el ejercicio del poder político, manifestado normalmente a través de representantes, pero que en este caso se ejerce directamente por los ciudadanos.

En relación a la definición de referéndum señala el Tribunal Constitucional que «es un instrumento de participación directa de los ciudadanos en los asuntos públicos, esto es, para el ejercicio del derecho fundamental reconocido en el art. 23.1 CE. No es cauce para la instrumentación de cualquier derecho de participación, sino específicamente para el ejercicio del derecho de participación política, es decir, de aquella participación que normalmente se ejerce a través de representantes y que, excepcionalmente, puede ser directamente ejercida por el pueblo» ${ }^{39}$.

37 Vid. en este sentido Loewenstein, K., Teoría de la Constitución, Barcelona, 1979, págs. 330-336.

${ }^{38}$ Los emplea como sinónimos Ripollés Serrano, M. ${ }^{a}$ R., «Notas acerca de la Ley Orgánica sobre regulación de las distintas modalidades de referéndum», en VV. AA., Estudios sobre la Constitución española de 1978, Valencia, 1980, págs. 325-329.

39 STC 103/2008, de 11 de septiembre, F. J. 2. Sobre esta Sentencia puede leerse el trabajo de Aguado Renedo, C., «Referéndum autonómico y jurisprudencia constitucional», UNED. Teoría y Realidad Constitucional, núm. 28, 2011, págs. 541-554. 
$\mathrm{Y}$ añade el Tribunal que el referéndum es «una forma de democracia directa y no una mera manifestación del fenómeno participativo que tanta importancia ha tenido y sigue teniendo en las democracias actuales y al que fue especialmente sensible nuestro constituyente, que lo ha formalizado como un mandato de carácter general a los poderes constituidos para que promuevan la participación en distintos ámbitos (arts. 9.2 y $48 \mathrm{CE}$ ) o como un verdadero derecho subjetivo (por ejemplo, arts. 27.5 y 7,105 y $125 \mathrm{CE}$ ) ${ }^{40}$.

En este sentido, el mismo Tribunal señala una clara diferencia entre lo que es el referéndum y lo que son las consultas como instrumento de participación del ciudadano. Podíamos concluir, que la finalidad del referéndum es ratificar la decisión tomada por el poder público y la consulta popular se utilizaría «en la fase de formación de la voluntad» para que posteriormente el poder público tome una decisión ${ }^{41}$. En alguna medida esta interpretación puede chocar con la constitucionalización del referéndum consultivo al que nos hemos referido anteriormente, esto es porque el art. $92 \mathrm{CE}$ «es uno de los preceptos más equívocos y polémicos de toda nuestra Constitución» y especialmente porque «es una norma sensiblemente imperfecta y asistemática» ${ }^{42}$.

En cualquier caso, el sentido que debe darse a la competencia para convocar consultas populares en el ámbito autonómico, de las que trataremos a continuación, es un sentido claramente distinto al del referéndum que se recoge en nuestra Constitución.

\section{LAS CONSULTAS POPULARES EN LOS ESTATUTOS DE AUTONOMÍA, ESPECIAL REFERENCIA AL CASO CATALÁN}

\section{La regulación autonómica de las consultas populares y la intervención del Tribunal Constitucional}

Como decíamos frente al referéndum que recoge nuestra Constitución se han regulado recientemente en el ámbito autonómico las consultas populares. La creación de las Comunidades Autónomas ha sido un proceso largo y para muchos autores aún inacabado. Hubo una etapa inicial que fue la de aprobación de los

40 Ibídem.

41 Bueno Armijo, A., «Consultas populares” y "referéndum consultivo”: una propuesta de delimitación conceptual y de distribución competencial», Revista de Administración Pública, núm. 177, septiembre-diciembre 2008, pág. 207.

42 Santamaría Pastor, J. A., «Comentario al artículo 92», en Garrido Falla, F. (Coord.), comentarios a la Constitución, Madrid, 1980, pág. 934. 
Estatutos (1979 a 1983), caracterizada por un distanciamiento cada vez mayor entre las Comunidades especiales y el resto de las Comunidades que accedieron por la vía ordinaria. Posteriormente comienza la etapa impulsada por los Acuerdos Autonómicos de 1992, recogidos en la Ley Orgánica 9/1992, de 23 de diciembre supone dar un paso más en el avance descentralizador que se prescribe en el texto de la Constitución ${ }^{43}$. Si la etapa anterior se caracterizó por sentar las bases del modelo, generalizando la autonomía política a los diecisiete territorios, en esta segunda etapa el objetivo fue acercar los niveles competenciales de aquellas Comunidades Autónomas que no alcanzaban los de las que tenían niveles competenciales superiores.

Sin embargo, las más importantes reformas estatutarias centraron la polémica a lo largo de la VIII Legislatura, que comenzó en 2004 y terminó en 2008. Se modificaron seis Estatutos de Autonomía ${ }^{44}$ : valenciano ${ }^{45}$, catalán ${ }^{46}$, balear ${ }^{47}$, andaluz ${ }^{48}$, aragonés ${ }^{49}$, castellano leonés ${ }^{50}$ y extremeño $0^{51}$. Algún autor ha señalado que esta etapa no ha supuesto una simple reforma de los Estatutos, sino una auténtica refundación de las Comunidades Autónomas ${ }^{52}$.

43 Vid. Arce JanÁriz, A., «La reforma de los Estatutos de Autonomía pactada en los Acuerdos Autonómicos de 1992», Revista Vasca de Administración Pública, núm. 40, 1994, págs. 9-32.

44 Posteriormente se aprobó una reforma de la Ley Orgánica de reintegración y amejoramiento del Régimen Foral de Navarra, a través de la LO 7/2010, de 27 de octubre, que supuso la adaptación del texto a la nueva realidad jurídico-política existente, pero que no se enmarca en el contenido de las reformas seguidas por los Estatutos mencionados. La última reforma afectó a Murcia, mediante la LO 7/2013, de 28 de noviembre, en este caso para incorporar al Estatuto la competencia del Gobierno murciano para dictar Decretos- Leyes.

45 Ley Orgánica 1/2006, de 10 de abril, de Reforma de Ley Orgánica 5/1982, de 1 de julio, de Estatuto de Autonomía de la Comunidad Valenciana (BOE núm. 86, de 11 de abril).

${ }^{46}$ Ley Orgánica 6/2006, de 19 de julio, de reforma del Estatuto de Autonomía de Cataluña (BOE núm. 172, de 20 de julio).

${ }^{47}$ Ley Orgánica 1/2007, de 28 de febrero, de reforma del Estatuto de las Illes Balears (BOE núm. 52, de 1 de marzo).

48 Ley Orgánica 2/2007, de 19 de marzo, de reforma del Estatuto de Autonomía para Andalucía ( $B O E$ núm. 68, de 20 de marzo).

49 Ley Orgánica 5/2007, de 20 de abril, de reforma del Estatuto de Autonomía de Aragón (BOE núm. 97, de 23 de abril).

${ }^{50}$ Ley Orgánica 14/2007, de 30 de noviembre, de reforma del Estatuto de Autonomía de Castilla y León (BOE núm. 288, de 1 de diciembre).

${ }^{51}$ Ley Orgánica 1/2011, de 28 de enero, de reforma del Estatuto de Autonomía de la Comunidad Autónoma de Extremadura (BOE núm. 25, de 29 de enero de 2011).

52 Así, señala Contreras Casado que la reforma del Estatuto Vasco, conocida como Plan Ibarrexte, que se presentó al finalizar la VII Legislatura (2000-2004), fue el principio de esa modificación del Estado de las Autonomías, pues «no se trataba en rigor de una reforma, sino de un replanteamiento de las relaciones de esa Comunidad con el Estado que desbordaba ampliamente el marco constitucio- 
Lo cierto es que en estos supuestos de reformas el impulso obedeció a un objetivo hasta el momento común que era el de incrementar las competencias de las Comunidades Autónomas, restringiendo las del Estado, especialmente en el caso de las competencias compartidas ${ }^{53}$. En todo caso, como ha señalado Argullol, «el nuevo proceso de reformas estatutarias presenta características muy distintas de las anteriores» porque este proceso de «reforma pretende identificar nuevos ámbitos competenciales y una diferente definición, al menos parcialmente, del régimen jurídico de competencias» ${ }^{54}$.

En los nuevos Estatutos están reguladas las consultas populares en los arts. 28 y 50.8 del Estatuto valenciano, en el art. 122 del Estatuto catalán, en los arts. 15.2 y 31.10 del Estatuto balear, en el art. 78 del Estatuto anda-

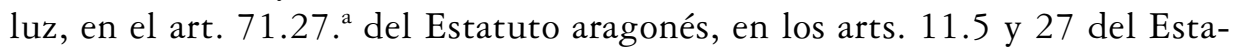
tuto castellano leonés y en el art. 9.1 del Estatuto extremeño. Además de estos Estatutos ya mencionaban las consultas populares los Estatutos de Asturias (art. 11), Canarias (art. 32), Murcia (art. 11.8) y La Rioja (art. 9.7) (5) $^{55}$

La competencia exclusiva de los Estatutos de Autonomía para la convocatoria de consultas populares supone una vez más la necesidad de hacer referencia al creciente ámbito competencial de las Comunidades y a la necesidad de señalar que aunque sí caben las consultas populares autonómicas hay que tener en cuenta ciertas cautelas. Esto es, se pueden celebrar estas consultas siempre que se cumplan una serie de requisitos, como son la «autorización del gobierno de la nación, sobre materia de competencia de la Comunidad Autónoma y como destinatarios a todo el censo electoral de la Comunidad ${ }^{56}$.

nal» y añade el mismo autor que lo grave del caso catalán no es tanto la modificación total del Estatuto por otro, sino «el espíritu de ruptura y de refundación que impregna todo el texto estatutario». Vid. Contreras Casado, M., «Las reformas de los Estatutos de Autonomía. Viejos y nuevos tiempos en la construcción del Estado autonómico» en Anuario jurídico de La Rioja., núm. 11, 2006, pág. 21.

53 En este sentido, Biglino Campos, P., «Reforma de la Constitución, reforma de los Estatutos de Autonomía y configuración constitucional del orden de competencias», Revista de las Cortes Generales, núm. 65, 2007, págs. 8-28.

54 Argullol Murgadas, E., «La reforma estatutaria: una primera aproximación», Revista de Administración Pública, núm. 174, septiembre-diciembre (2007), pág. 200.

55 Por otra parte, también en el ámbito autonómico se recogen otras vías de participación ciudadana, tanto la iniciativa legislativa popular como ya hemos señalado, como la posibilidad de participar en el procedimiento legislativo o el derecho de petición. Vid. un estudio de todas estas vías de participación en MARTín NÚÑEZ, E., «Los derechos de participación política y administrativa en la Constitución y en los Estatutos de Autonomía: especial referencia al estatuto de autonomía de Cataluña», Revista Espaço Jurídico, vol. 14, núm. 3, Edição Especial, 2013, págs. 113-132.

56 Pérez Sola, N., «La competencia exclusiva de las Comunidades Autónomas en materia de consultas populares», UNED. Teoría y Realidad Constitucional, núm. 24, 2009, pág. 453. En similar sentido se pronunciaba el Consejo de Estado en su Dictamen 1119/2008, de 3 de julio, en 
Es ya relevante, la jurisprudencia constitucional acerca de la competencia de las Comunidades para convocar consultas populares ${ }^{57}$. Recientemente el Tribunal ha tenido también ocasión de pronunciarse en relación al tema tanto en el caso canario ${ }^{58}$, como en el caso catalán, al que nos referiremos posteriormente.

En estos casos el Tribunal ha reiterado la posibilidad de que las Comunidades Autónomas puedan realizar consultas populares que son expresión de una «democracia participativa»y «no son ya expresión del derecho fundamental» 59 Y, precisa el Tribunal que «la noción de referéndum es, a efectos competenciales, de carácter material, y bastará para identificarlo, por lo tanto, con que se esté ante un llamamiento a un cuerpo electoral que, aunque distinto acaso al definido por aquella legislación orgánica, abarque al conjunto de la ciudadanía de una Comunidad Autónoma o de un ente territorial local y con que se configure un procedimiento y unas garantías que, aunque no sean idénticos a los previstos en

relación a la presentación del recurso de inconstitucionalidad de la Ley del País Vasco 9/2008, de 27 de junio: «Todos los posibles referendos autonómicos, incluidos los consultivos, están regulados por la Ley Orgánica 2/1980, de 18 de enero, y, en su caso, por diversas normas de los Estatutos de Autonomía. La consulta regulada en la Ley es un referéndum consultivo, sujeto a autorización del Estado. Ello implica que debe regirse por la Ley Orgánica 2/1980, de 18 de enero, de lo que se desprende que la consulta no puede ser regulada por Ley autonómica, porque no son admisibles otros referendos que los previstos en la Constitución, la cual encomienda su autorización al Estado y reserva su regulación a Ley orgánica (artículo $92 \mathrm{CE}$ )».

57 En primer lugar, son de destacar tanto la STC 103/2008, de 11 de septiembre, que ya hemos citado, que fue dictada por el Tribunal contra la Ley del Parlamento Vasco 9/2008, de 27 de junio, de convocatoria y regulación de una consulta popular al objeto de recabar la opinión ciudadana en la Comunidad Autónoma del País Vasco sobre la apertura de un proceso de negociación para alcanzar la paz y la normalización política, como las referencias que se incluyen en la STC 31/2010, de 28 de junio, dictada en relación al Estatuto catalán de 2006. Aquí el grave problema, entre otros muchos que se han señalado, está en la ejecución del contenido de esta última Sentencia pues «en la medida en que se trata de una sentencia interpretativa, serán los actores políticos implicados (titulares de los poderes centrales y del poder autonómico catalán) los que deberán aplicar el Estatuto en el sentido indicado por el Tribunal Constitucional» TAJADuRA TEJADA, J., «El pronunciamiento del Tribunal Constitucional sobre el preámbulo del Estatuto de Autonomía de Cataluña: Nación, realidad nacional y derechos históricos», UNED. Teoría y Realidad Constitucional, núm. 27, 2011, pág. 445.

58 Así lo ha hecho en la STC 137/2015, de 11 de junio de 2015 en relación al Decreto del Gobierno de Canarias 95/2014, de 25 de septiembre, por el que se aprueba el Reglamento de las consultas a la ciudadanía en asuntos de interés general de competencia de la Comunidad Autónoma de Canarias y en la STC 147/2015, de 25 de junio de 2015 en relación con diversos preceptos del Decreto del Presidente del Gobierno de Canarias 107/2014, de 2 de octubre, por el que se convoca consulta ciudadana mediante pregunta directa en el ámbito territorial de Canarias.

59 STC $137 / 2015$, de 11 de junio de 2015, F. J. 4. 
la legislación electoral estatal, comporten un grado de formalización de la opinión ciudadana que sea materialmente electoral ${ }^{60}$.

A la luz de la doctrina del Tribunal estamos de acuerdo en que «lo que caracteriza el referéndum es la atribución al cuerpo electoral de una expresión, directa y legítima, sobre el asunto — especial transcendencia política y no administrativa - que se le somete a consideración ${ }^{61}$. Por el contrario, «una consulta popular no referendaria es un instrumento de participación ciudadana dirigido a conocer la opinión sobre cualquier aspecto de la vida pública, con transcendencia política o no, que puede materializarse a través de diversos instrumentos» ${ }^{62}$.

Si parece que «las Comunidades Autónomas en uso de sus facultades de regulación de sus instituciones propias [ex art. 148.1.1a) de la CE] pueden crear las formas de consulta popular que consideren oportunas dentro de sus ámbito de competencias y dotarlas de una regulación propia al margen de la LOMR (Ley Orgánica de regulación de las distintas modalidades de referéndum), a salvo claro está del régimen de autorización ${ }^{63}$.

El Tribunal vuelve sobre este punto, diferenciando claramente lo que es referéndum como proyección del derecho fundamental del art. 23 CE y lo que son las formas de consultas populares. Se extraen varios rasgos definitorios relevantes $^{64}$ :

1) «El primero de sus rasgos definidores radica, pues, en que, a través del referéndum, se produce un llamamiento del poder público a la ciudadanía para ejercer el derecho fundamental de participación en los asuntos públicos reconocido en el art. 23.1 CE. El destinatario de la consulta es el conjunto de ciudadanos que tienen reconocido el derecho de sufragio activo en un determinado ámbito territorial o, lo que es lo mismo, el cuerpo electoral».

2) «Un segundo elemento ínsito en el concepto de referéndum estriba en que la opinión del cuerpo electoral se expresa por medio del sufragio emitido en el curso de un proceso electoral, a fin de que el resultado de la consulta pueda jurídicamente imputarse a la voluntad general de la correspondiente comunidad

${ }^{60}$ STC 31/2015, de 25 de febrero de 2015, F. J. 8.

${ }^{61}$ Martín NúÑEZ, E., «El referéndum y las consultas populares en las Comunidades Autónomas y municipios», Revista Vasca de Administración Pública, núm. 94. Septiembre-diciembre 2012, pág. 107.

${ }^{62}$ Ibídem.

63 Pérez Alberdi, M. ${ }^{a}$ R., «Los derechos de participación en los Estatutos de Autonomía reformados recientemente. (Especial consideración al Estatuto de Autonomía para Andalucía)», Revista de Derecho Político (UNED), núm. 73, septiembre-diciembre 2008, pág. 198.

${ }^{64}$ STC 31/2015, de 25 de febrero, F. J. 5. 
política y, de este modo, considerarse una genuina manifestación del derecho fundamental de participación política reconocido en el art. 23.1 CE».

En definitiva, compete con exclusividad al Estado la convocatoria de referéndum, en tanto se apela a que los ciudadanos ejerzan el derecho fundamental de participación en los asuntos públicos emitiendo su opinión, vinculante o no, sobre una determinada cuestión. Pero también es competencia del Estado su regulación, como se desprende del tenor constitucional, puesto que el régimen jurídico del referéndum está sujeto a una reserva de Ley Orgánica (así lo señala expresamente el art. 92.3 CE y se deduce de la reserva del art. 81.1 CE en tanto es desarrollo de los derechos fundamentales y las libertades públicas). Por otra parte, la Constitución atribuye al Estado, como competencia exclusiva, la «autorización para la convocatoria de consultas populares por vía de referéndum» (art. 149.1.32 CE), competencia que, de conformidad con lo señalado por el Tribunal Constitucional, «no puede limitarse a la autorización estatal para la convocatoria de consultas populares por vía de referéndum, sino que ha de extenderse a la entera disciplina de esa institución, esto es, a su establecimiento y regulación» ${ }^{65}$.

Por eso en lo que se refiere a las Comunidades Autónomas «no cabe en nuestro ordenamiento constitucional, en materia de referéndum, ninguna competencia implícita, puesto que en un sistema, como el español, cuya regla general es la democracia representativa, solo pueden convocarse y celebrarse los referendos que expresamente estén previstos en las normas del Estado, incluidos los Estatutos de Autonomía, de conformidad con la Constitución» ${ }^{66}$.

\section{La utilización en Cataluña de la competencia en consultas populares}

Desde la aprobación del Estatuto Catalán, con el conflicto que supuso la STC 31/2010, de 28 de junio y especialmente desde que el 19 de diciembre de 2012 fecha en la que Convergencia i Unio (CiU) y Esquerra Republicana de Cataluña (ERC) firman un pacto de gobernabilidad con el asunto de la soberanía como punto fuerte, los poderes públicos catalanes comienzan a realizar determinadas actuaciones cuyo fin es la independencia. Para conseguir esa independencia se está utilizando, entre otros medios, la convocatoria de consultas populares.

En relación al asunto que nos ocupa, el art. 122 del Estatuto de Cataluña, establece que corresponde a la Generalitat «la competencia exclusiva para el

\footnotetext{
${ }^{65}$ STC 31/2010, de 28 de junio, F. J. 69.

${ }^{66}$ STC 103/2008, de 11 de septiembre, F. J. 3.
} 
establecimiento del régimen jurídico, las modalidades, el procedimiento, la realización y la convocatoria por la propia Generalitat o por los entes locales, en el ámbito de sus competencias, de encuestas, audiencias públicas, foros de participación y cualquier otro instrumento de consulta popular, con excepción de lo previsto en el artículo 149.1.32 de la Constitución».

Y en la STC 31/2010 explica el Tribunal que de esta manera interpretada, «la competencia para el establecimiento del régimen jurídico, las modalidades, el procedimiento, la realización y la convocatoria por la propia Generalitat o por los entes locales, en el ámbito de sus competencias, de encuestas, audiencias públicas, foros de participación y cualquier otro instrumento de consulta popular», atribuida a la Generalitat por el art. 122 EAC, es perfectamente conforme con la Constitución, en el bien entendido de que en la expresión «cualquier otro instrumento de consulta popular» no comprende el referéndum.

La competencia de Cataluña de convocar consultas populares, que se recoge en el art. 122 de su Estatuto no puede ampliarse y en su caso no puede incidir sobre «sobre cuestiones fundamentales resueltas con el proceso constituyente y que resultan sustraídas a la decisión de los poderes constituidos», pues en el caso de que se quisiera modificar el contenido del texto constitucional deberán utilizarse los procedimientos previstos para ello en el mismo texto y no proceder a realizar una mutación constitucional. En nuestro sistema la mutación constitucional supone un claro ataque a la Constitución pues supone «el cambio que modifica el contenido de las normas constitucionales de modo que la norma, conservando el mismo texto, recibe una significación diferente» ${ }^{67}$.

La intervención del Tribunal Constitucional, en relación a Cataluña ha sido frecuente. Así se ha pronunciado a través de la STC 31/2015, de 25 de febrero de 2015 por la que se resuelve el recurso de inconstitucionalidad interpuesto por el Presidente del Gobierno en relación con diversos preceptos de la Ley del Parlamento de Cataluña 10/2014, de 26 de septiembre, de consultas populares no referendarias y otras formas de participación ciudadana ${ }^{68}$; en la STC 32/2015, de 25 de febrero de 2015 por la que resuelve la impugnación del Decreto del Presidente de la Generalitat de Cataluña 129/2014, de 27 de septiembre, así como de sus anexos, de convocatoria de la consulta no referendaria sobre el futuro político de Cataluña y en la STC 138/2015, de 11 de junio de 2015 que resuelve la impugnación formulada por el Gobierno de la Nación respecto de las

\footnotetext{
${ }^{67}$ Hesse, K., Escritos de Derecho Constitucional, Madrid, 1992, pág. 85.

68 Vid. sobre esta Ley Alonso De Antonio, A. L., Análisis constitucional de la Ley catalana de consultas populares no refrendarias y otras formas de participación ciudadana, Cizur Menor (Navarra), 2015 .
} 
actuaciones de la Generalitat de Cataluña relativas a la convocatoria a los catalanes, para que manifiesten su opinión sobre el futuro político de Cataluña el día 9 de noviembre de 2014.

No cabe duda que en este asunto Cataluña ha intentado conseguir, y probablemente seguirá intentándolo, lo que había sucedido en Escocia: la autorización para celebrar un referéndum con fines secesionistas ${ }^{69}$. Sin embargo, la situación ha sido claramente diferente. Recordemos que en Escocia el celebrado el 18 de septiembre fue legal y válidamente convocado en virtud de la Scottish Independence Referendum Act, de 17 de diciembre de 2013 y la Sección V de la Scotland Act de 1998 (modificada previamente al efecto por la Scotland Act Modification of Schedule 5 Order in Council, de 12 de febrero de 2013) ${ }^{70}$.

Creemos que la consulta que se celebró en Cataluña fue un intento de secesión y que por ello «no es ni mucho menos una decisión política más, homologable a cualquier otra de las que se adoptan por decenas cada día en una democracia moderna». Es una decisión de gran trascendencia, «sobre el ser de la nación y sobre el fundamento de la Constitución y requiere ser tratada con la delicadeza propia de las cuestiones existenciales» ${ }^{71}$.

$\mathrm{Y}$ aunque no es adecuada la identificación del caso catalán con lo que ha sucedido en Escocia, si es conveniente tener en cuenta que el ejemplo escocés muestra lo desafortunada que fue dicha decisión jurídico-política, puesto que no ha servido para que desaparezca el problema escocés, sino que ha servido para que aparezcan nuevos visos que lo hacen aún más complicado de resolver ${ }^{72}$. En el caso español es necesario llegar a un consenso, en el que se evite la ruptura puesto que «un referéndum convocado unilateralmente no permitiría tal cosa. Además, cuando se llega al acuerdo de celebrar un referéndum de independencia y este es negativo, los actores favorables a la independencia deberían aceptar que

69 «Es Cataluña menos que Escocia? ¿Es Cataluña menos nación y está menos movilizada que Escocia para decidir su futuro?». Así se lo preguntaba el Presidente Artur Mas al Presidente Rajoy en una comparecencia pública en septiembre del 2014. Fuente: El País, 19 de septiembre de 2014 (disponible en http://ccaa.elpais.com/ccaa/2014/09/19/catalunya/1411125900_190321. html; última consulta el 27/04/2016).

${ }^{70}$ Los antecedentes del proceso político que ha desembocado en la celebración del referéndum pueden consultarse en Dorrego De Carlos, A., «El Referéndum sobre la independencia de Escocia», Cuadernos de Pensamiento Político. FAES, núm. 34, abril/junio de 2012, págs. 85-122.

71 Astarloa Huarte- Mendicoa, I., «El futuro es ahora», ABC, de 27 de septiembre de 2014.

72 Una comparación se suele hacer también con los referéndums celebrados en Quebec, vid. por todos López BASAguren, A., «La secesión de territorios en la Constitución española», Revista de Derecho de la Unión Europea, núm. 25, julio-diciembre 2013, págs. 87-106. 
la cuestión no se vuelva a plantear en un tiempo razonable (en una generación, por ejemplo)» $»^{73}$.

Por parte de los que propugnan la independencia se utiliza el principio democrático y como parte de él el derecho a decidir y la celebración de consulta en este asunto. Frente a este principio desaparece el principio de unidad, entre otros, y se olvida que las democracias constitucionales, que son representativas, están «sometidas a reglas y procedimientos, (...) en las que el papel del referéndum es configurado por la propia Constitución $»^{74}$.

Claramente la democracia representativa y los principios básicos del Estado de Derecho se están deteriorando, entre otros factores, «por la falta de lealtad constitucional mostrada por determinadas autoridades públicas y ciertos dirigentes políticos, la escasa convicción (cuando no, a veces, la simple ausencia de la misma) con que partidos y gobiernos «nacionales» han comparecido en el debate de las ideas frente a partidos y gobiernos «nacionalistas», la fusión esporádica entre «izquierda» $\mathrm{y}$ «nacionalismo», el confuso discurso intelectual sobre el derecho de autodeterminación a partir de una errónea concepción del significado de la democracia constitucional, el uso frecuente de la mentira como elemento de agitación y propaganda en los mensajes políticos, e incluso la actitud, generalmente extendida, de escaso respeto a las instituciones públicas $\gg^{75}$.

\section{A MODO DE CONCLUSIÓN}

La estructura territorial del Estado se establece en el art. $2 \mathrm{CE}$, que proclama los principios esenciales del sistema: unidad, autonomía y solidaridad. Precisamente, sin una definición clara del modelo propuesto, se configura una estructura territorial de naturaleza imprecisa, cuyos elementos quedan regulados en el Título VII del propio texto. El Estado español es, por tanto, un Estado asentado sobre la Nación española, derecho originario, y el derecho a la autonomía es un derecho derivado de la Constitución y por tanto, subordinado a la soberanía nacional. En este mismo sentido, el reconocimiento constitucional, plasmado en los Estatutos de Autonomía, supone dotar a éstos de un carácter de norma subor-

73 SÁnchez Ferro, S., «El referéndum de independencia escocés: ¿evolución o revolución del Derecho constitucional británico?», Revista Española de Derecho Constitucional, núm. 103, enero-abril (2015), pág. 152.

74 Castellà Andreu, J. M. a , «La secesión catalana, entre la política y el Derecho», Anuario Facultad de Derecho - Universidad de Alcalá, núm. VII, 2014, pág. 237.

75 Aragón Reyes, M., «Problemas del Estado autonómico», en Revista Asamblea, núm. 31, 2014, pág. 15. 
dinada al texto constitucional, y al margen de apreciaciones políticas, jurídicamente es indefendible otorgar a los Estatutos rango similar al de la Constitución. Así en palabras del Tribunal Constitucional, «al igual que el resto del ordenamiento jurídico, debe ser interpretado siempre de conformidad con la Constitución y que, por ello, los marcos competenciales que la Constitución establece no agotan su virtualidad en el momento de aprobación del Estatuto de Autonomía, sino que continuarán siendo preceptos operativos en el momento de realizar la interpretación de los preceptos de éste a través de los cuales se realiza la asunción de competencias por la Comunidad Autónoma» ${ }^{76}$.

El art. 1.1 CE señala que España es un Estado de Derecho «que propugna como valores superiores de su ordenamiento jurídico la libertad, la justicia, la igualdad y el pluralismo político». La democracia es un valor, pero nunca en aras de la defensa de la democracia se puede ir ni contra el Estado de Derecho ni contra las instituciones representativas. Nuestro orden constitucional supone derechos fundamentales, separación de poderes, imperio de la ley, democracia parlamentaria y representativa, respeto a la justicia y, por supuesto, poderes limitados y controlados. Y por ello debe quedar claro que el «funcionamiento democrático del Estado exige así la participación de los ciudadanos no sólo en el ámbito tradicional de las instituciones representativas del Estado y en el de las instituciones de participación política directa (democracia política) sino en todos los procesos decisionales públicos, estableciendo cauces de información, transparencia, comunicación y control de los ciudadanos respecto a los poderes públicos (democracia participativa), concretándose así los derechos de participación y/o de buena administración ${ }^{77}$.

Pero el Estado de Derecho que nuestra Constitución proclama no puede permitir que unilateralmente una parte del Estado pervierta el acuerdo que supone su misma existencia. Así lo ha señalado el Tribunal Constitucional al indicar que la «Constitución no aborda ni puede abordar expresamente todos los problemas que se pueden suscitar en el orden constitucional, en particular los derivados de la voluntad de una parte del Estado de alterar su estatus jurídico. Los problemas de esa índole no pueden ser resueltos por este Tribunal, cuya función es velar por la observancia estricta de la Constitución. Por ello, los poderes públicos y muy especialmente los poderes territoriales que conforman nuestro Estado autonómico son quienes están llamados a resolver mediante el diálogo y la cooperación los problemas que se desenvuelven en este ámbito. El

${ }^{76}$ STC 18/1982, de 4 de mayo, F. J. 1.

77 Martín NúÑEz, E., «Los derechos de participación política y administrativa en la Constitución y en los Estatutos de Autonomía...», cit., pág.114. 
concepto amplio de diálogo, por otra parte, no excluye sistema o institución legítima alguna capaz de aportar su iniciativa a las decisiones políticas, ni ningún procedimiento que respete el marco constitucional. A este Tribunal incumbe únicamente, a iniciativa de las partes legitimadas para recabar su intervención, velar porque los procedimientos que se desarrollen en el curso de este diálogo se ajusten a los requisitos exigidos por la Constitución» ${ }^{78}$. Y añade el Tribunal que «de esto se infiere que en el marco de la Constitución una Comunidad Autónoma no puede unilateralmente convocar un referéndum de autodeterminación para decidir sobre su integración en España» ${ }^{79}$.

Quedan aún pasos pendientes por dar, que nos parecen urgentes, pues ya advertía el mismo Consejo de Estado acerca de los peligros del Estado de las Autonomías. Así señalaba que «los riesgos de crisis que la apertura del sistema genera se hacen, además, más graves, por razones obvias, cuanto más se acerca el ámbito competencial de las Comunidades al máximo admitido por la Constitución. En esta situación, cerca de la que nos encontramos ya, cualquier propuesta de reforma que pretenda ampliar las competencias de la Comunidad respectiva puede dar lugar a acusaciones de que con ella se pretenden rozar o violentar, de manera deliberada o no, los límites constitucionales. Con ello, una cuestión estrictamente jurídica se lleva al debate político, con daño tanto para el Derecho como para la política» ${ }^{80}$. Habría que intentar evitar que la debilidad del sistema arrastrara lo conseguido hasta ahora y debería otorgarse al texto constitucional la facultad de ser el que establezca la organización territorial del poder y que esa facultad no descansase en las Comunidades. Por todo ello el principio de seguridad jurídica aconseja prudencia en la expansión normativa autonómica.

Es cierto que vivimos tiempos en los que la inseguridad, tanto económica, como social, como política, proyecta oscuridad sobre nuestro futuro. Subyace la idea de que se necesita una reforma constitucional. Varias formaciones políticas en la campaña electoral de las elecciones generales de diciembre de 2015 , así como en las recientes de junio de 2016, han barajado la necesidad de una serie de reformas constitucionales. A la vista del resultado de las elecciones, de

${ }^{78}$ STC 42/2014, de 25 de marzo, F. J. 4 b). Esta Sentencia fue dictada a raíz de la Declaración de Soberanía y el Derecho a Decidir del Pueblo de Cataluña aprobada por el Parlamento catalán en octubre de 2012, por ochenta y cinco votos a favor y cuarenta y uno en contra.

79 STC 42/2014, de 25 de marzo, F. J. 3a). Sobre el «derecho a decidir» se han escrito varios trabajos especialmente en defensa de la independencia vid. por todos BARCELó I SERRAMALERA, M., Correjta Torrens M., González Bondia, A., López Hernández, J. y Vilajosana Rubio, J. M., El derecho a decidir. Teoría y práctica de un nuevo derecho», Barcelona, 2015.

80 Informe del Consejo de Estado sobre modificaciones de la Constitución, febrero de 2006, pág. 144 . 
la fallida investidura del Presidente, de la disolución de las Cortes y de la convocatoria de unas nuevas elecciones generales la cuestión no va a ser fácil. Para reformar la Constitución necesitamos apelar al consenso amplio entre los partidos y los ciudadanos y a la prudencia, huyendo de la precipitación, de la improvisación y de la demagogia. La reforma de nuestro texto constitucional, que, a pesar de sus debilidades, ha otorgado al pueblo español las mayores cotas de libertad e igualdad de su historia, constituye una operación jurídica delicada, que sólo debe abordarse mediante un diseño sólido previo y un pacto social y político.

Por eso, hay que poner el acento en reafirmar los valores que animaron a nuestra Constitución y a nuestro Estado de Derecho, especialmente en la unidad y la solidaridad que siguen siendo hoy válidos para evitar la fragmentación. Peligroso es equivocarse en realizar reformas precipitadas, pero más peligroso puede ser no realizar las necesarias. Este es el asunto pendiente de nuestro sistema constitucional y una labor por la que las generaciones futuras podrán pedirnos cuentas.

Title:

Direct participation of citizens in the Spanish Constitution and the competency in popular consultations in some Autonomous Communities

\section{Summary:}

I. ABOUT DIRECT DEMOCRACY AND CITIZEN PARTICIPATION. II. REFERENDUM AS A MEANS OF DIRECT PARTICIPATION IN THE CONSTITUTION OF 1978. III. POPULAR CONSULTATIONS IN THE STATUTE OF AUTONOMY, SPECIAL REFERENCE TO CATALONIA. 1. The autonomic regulation of the popular consultation and the intervention of the Constitutional Court. 2. The use in Catalonia of competition in popular consultations. IV. CONCLUSION.

\section{Resumen:}

En el presente estudio se aborda un análisis sobre las características de la democracia representativa y de la democracia directa, especialmente 
sobre el referéndum y su diferencia con respecto a las consultas populares. Algunas Comunidades Autónomas tienen competencia para convocar consultas populares, lo que ha supuesto, especialmente en el caso de Cataluña, que el Tribunal Constitucional haya tenido que aclarar el alcance de dichas consultas y su inconstitucionalidad cuando se pretende equipararlo al referéndum.

\begin{abstract}
:
In the present study, we analyze the characteristics of representative democracy and direct democracy, especially on the referendum and its difference from the popular consultations. Some Autonomous Communities have the power to call referendums, which has led, especially in the case of Catalonia, the Constitutional Court has had to clarify the scope of such consultations and unconstitutional when trying to equate the referendum.
\end{abstract}

\title{
Palabras clave:
}

Constitución, democracia, referéndum, consultas populares, Cataluña, crisis de la democracia.

\section{Keywords:}

Constitution, democracy, referendum, popular consultations, Catalonia, democracy crisis. 
